\title{
Chronic kisspeptin delays puberty and reduces feed intake and body weight in female rats
}

\author{
Sriravali Sathagopam, Meenal Prabhakar Ullewar, Rakhi Harne and Sathya Velmurugan* \\ National Institute of Animal Biotechnology (NIAB), Hyderabad 500049, India
}

Received February 2, 2021

Revised March 15, 2021

Accepted March 15, 2021

\section{*Correspondence \\ Sathya Velmurugan \\ E-mail: sathyavet@gmail.com}

ORCID

https://orcid.org/0000-0003-0769-8424

\begin{abstract}
Kisspeptin is a key player in the central control of reproductive axis. Central administration of kisspeptin has been shown to advance puberty in rats. Stimulation of hypothalamic GnRH pulse generating mechanism by kisspeptin has been proposed to be the mechanism behind the onset of puberty. We hypothesized that chronic high doses of kisspeptin administration suppresses the reproductive axis and hence delays the pubertal onset. Hence, we investigated the effect of peripheral administration of chronic high doses of kisspeptin on pubertal onset, feed intake and body weight in female rats. Rats were treated with saline or kisspeptin (100 nmoles per day; intraperitoneal) for 26 days (day 25 to day 50 postnatal) and the day of vaginal opening was marked as day of puberty. Kisspeptin treated rats had delayed pubertal onset and reduced feed intake and body weight. Gonadal GPR54 mRNA was reduced suggesting that chronic high doses of kisspeptin may suppress the reproductive functions possibly by downregulation of GPR54 receptor. However, delay in puberty due to reduction in feed intake and body weight could not be ruled out in this study. Further, our study emphasizes the importance of dosage and duration of kisspeptin administration in the manipulation of reproductive axis. Our study, for the first time, suggests that kisspeptin and its analogues, if proven beneficial, could be used to treat precocious puberty in children. It appears that, though a promising tool for enhancing fertility, kisspeptin acts as a double-edged sword and has to be cautiously used to manipulate reproduction.
\end{abstract}

Keywords: hypothalamo-pituitary-gonadal axis, kisspeptin, puberty

\section{INTRODUCTION}

Kisspeptin is a key controller of reproductive axis upstream to GnRH (Pinilla et al., 2012). Neuroendocrine control of GnRH neurons by kisspeptin orchestrates the sequences that take place during the oestrous cycle (Beltramo et al., 2014). In the hypothalamus, kisspeptin is expressed in arcuate nucleus and rostral periventricular region in rats (Overgaard et al., 2013). Kisspeptins, a group of peptides of 54,14, 13 and 10 amino acid length, are cleaved from a 154 amino acid peptide coded by Kiss1 gene. The decapeptide containing - $\mathrm{COOH}$ terminal is required for the functional activation of the kisspeptin receptor, the G-protein coupled receptor-54 (GPR-54).

Upon central or peripheral administration of kisspeptin, hyptohalamo-pituitary-gonadal axis is activated via the activation of hypothalamic GnRH neurons (Irwig et al., 2004; Matsui et al., 2004). Intracerebroventricular (i.c.v) administration of kisspeptin for 6 days induces vaginal opening (VO) in immature females rats ( $1 \mathrm{nmol}$ mouse 
kisspeptin 10 (110-119)-NH2 into lateral ventricle every 12 h during days 26 to 31) (Navarro et al., 2004). Comparably, central infusion of Peptide 234 (p234), a kisspeptin antagonist ( $0.4 \mathrm{nmol} / \mathrm{h}$ for 7 days during days 30 to 36), to pubertal females delayed VO (Pineda et al., 2010). Chronic low doses of kisspeptin $(50 \mathrm{pmol}$ i.c.v. from day 26 to 60 ) has also been shown to advance puberty in rats (Sahin et al., 2015). Kisspeptin restores VO in undernourished female rats (1 nmol mouse kisspeptin 10 (110-119)$\mathrm{NH} 2$ i.c.v. into lateral ventricle every $12 \mathrm{~h}$ during days 30 to 37) (Castellano et al., 2005). However, higher doses of kisspeptin was ineffective in advancing puberty in rats. Continuous i.c.v. administration of $7.5 \mathrm{nmol} / \mathrm{d}$ of kisspeptin for 7 days during days 31 to 37 and intraperitoneal (i.p) administration of $100 \mathrm{nmol} / \mathrm{d}$ for 14 days during days 26 to 40 had no effect on VO (Roa et al., 2008; Alcin et al., 2011). Hence, we hypothesized that chronic and high doses of kisspeptin delays puberty in female rats. As higher doses of kisspeptin $(50 \mathrm{nmol} / \mathrm{d}$ for 13 days or one day, s.c) has been shown to cause testicular degeneration in male rats (Thompson et al., 2006 and 2009), we also hypothesized that chronic high doses of kisspeptin will result in ovarian degeneration in female rats.

Kisspeptin has been shown to excite anorexigenic proopiomelanocortin (POMC) neurons and inhibit orexigenic Neuropeptide Y (NPY) neurons (Fu and van den Pol, 2010). However, the effect of kisspeptin on energy metabolism and body weight remains inconclusive. Central infusion of kisspeptin antagonist p234 did not affect body weight (Pineda et al., 2010). On the contrary, Kiss1r KO female mice had higher body weight, leptin level and adiposity and had impaired glucose tolerance (Tolson et al., 2014). While Castellano et al. (2005) reports that feed intake was not affected by centrally given kisspeptin in rats, Stengel et al. (2011) reports that central kisspeptin dose dependently decreases feed intake in mouse after an overnight fast. Central kisspeptin reduces food intake and bodyweight (Sahin et al., 2015). However, peripheral administration of kisspeptin $(10 \mu \mathrm{g} /$ mouse $)$ did not affect feed intake (Stengel et al., 2011). Here we examined whether chronic high doses of peripheral kisspeptin affect feed intake and body weight in pubertal rats.

\section{MATERIALS AND METHODS}

\section{Ethical approval}

The experiments described here were approved by Institutional Animal Ethical Committee of Teena Biolabs Private Limited, Hyderabad, India, where the experiments were conducted. The experiments follow the regulations of Committee for the Purpose of Control and Supervision of Experiments on Animals (CPCSEA), India.

\section{Animals}

Sprague-Dawley female pre-pubertal rats were obtained and housed (2-3 rats per cage) at Teena Biolabs Private Limited, Hyderabad, India. They were maintained at a temperature of $24 \pm 1 \mathrm{C}$ and relative humidity of $62 \pm 2 \%$ with $12 \mathrm{~h}$ light/dark cycle (lights on at $700 \mathrm{~h}$ ). They were given water and pelleted feed ad libitum.

\section{Drug}

Kisspeptin (Tyr-Asn-Trp-Asn-Ser-Phe-Gly-Leu-ArgPhe-NH2; human kisspeptin-10; also called Metastin 4554) was synthesized at Auro Peptides, Hyderabad. It was dissolved in distilled water at the rate of $1 \mathrm{mg} / \mathrm{mL}$ and stored at $-20^{\circ} \mathrm{C}$. This was further diluted in saline and administered intraperitoneally at a dose rate of 100 nmoles/ rat per day in $200 \mu \mathrm{L}$ volume of saline.

\section{Experimental design}

Rats were weighed and feed intake was monitored from day 22 (day 0 is the day of birth; day 21 is the day of weaning) until day 60. From daily feed intake, cumulative feed intake was calculated and averaged. Saline (n $=8)$ or kisspeptin-10 ( $=9)$ was administered intraperitoneally from day 25 to day 50 (26 days) between 9:00 and 10:00 hours. Complete canalization of vagina (i.e. vaginal opening; VO), an external indication of puberty, was checked by visual examination from day 26 onwards. The day when complete opening of vaginal canal was observed was marked as day of puberty. On day 66, after all the animals attained puberty, they were administered either saline or kisspeptin (100 nmoles/rat, i.p) and blood samples were collected retro-orbitally an hour after injection to study LH and oestradiol response to kisspeptin and swabs were collected for vaginal cytology. Subsequently, the animals were sacrificed in $\mathrm{CO}_{2}$ chamber. Plasma was immediately separated and stored at $-20^{\circ} \mathrm{C}$ until analyzed 
for LH and oestradiol concentration by ELISA. Heart, liver and gonads were weighed for calculating organ coefficients (weight in $\mathrm{g}$ of organs per $100 \mathrm{~g}$ body weight). Gonads were preserved in $10 \%$ formalin for histopathology and GPR54 immunohistochemistry, in liquid nitrogen for GPR54 Western blot analysis, and in RNAlater ${ }^{\circledR}$ RNA Stabilization Solution (Invitrogen) for GPR54 mRNA expression by real time (quantitative) PCR.

\section{ELISA}

Plasma LH and oestradiol concentration was measured using ELISA kits specified for rats (Cusabio). The assay was performed as per manufacturer's instructions. Standard curve was constructed using the given standards and the results were extrapolated.

\section{Histopathology}

Using standard protocol, paraffin embedded ovaries and uteri were sectioned and stained using haematoxylin and eosin. The number of follicles and corpus luteum (CL) in the ovaries were counted. Gonads were studied for pathological changes, if any.

\section{Western blot}

Ovarian and uterine samples were lysed using RIPA buffer supplemented with protease and phosphatase inhibitors in tissue homogenizer; tissue lysate was sheared by ultra-sonication and then centrifuged at 9,000 rpm for 20 minutes. The proteins in the supernatant were quantified by Bradford assay and were resolved by $15 \%$ SDS-PAGE and transferred on to PVDF membrane. The membranes were blocked overnight using $5 \%$ nonfat milk at $4{ }^{\circ} \mathrm{C}$ and subsequently probed with GPR54 primary antibody (GeneTex) for $2 \mathrm{hrs}$ at $4^{\circ} \mathrm{C}$ and then with HRP conjugated secondary antibody for 2 hrs. The signals were visualized by chemiluminescent detection (Amersham ECL Prime Western blotting kit; GE Healthcare). The membrane was stripped using stripping buffer (Restore Western Blot Stripping buffer; Thermo Scientific) and re-probed for $\beta$-actin which served as control.

\section{Real time PCR}

Total RNA was isolated from the ovarian and uterine samples (RNeasy Mini Kit; Qiagen) and reverse transcription was carried out (PrimeScript First Strand cDNA Synthesis Kit; Takara) in a total volume of $20 \mu \mathrm{L}$ according to the manufacturer's protocols. The resultant cDNA was amplified using a SYBR ${ }^{\circledR}$ Green qPCR Master Mix Kit (Applied Biosystems) and was quantified using ABI Prism ${ }^{\circledR}$ 7500 sequence detection system (Applied Biosystems). The specific primer details are shown in Table 1 (Integrated DNA Technologies). The PCR reaction mixture consisted of $2 \mu \mathrm{L}$ of cDNA (all samples are set to $40 \mathrm{ng} / \mu \mathrm{L}$ ), $1 \mu \mathrm{L}$ each of specific primers $(10 \mu \mathrm{M})$ and $4 \mu \mathrm{LSYBR}^{\circledR}$ Green Master Mix in a total volume of $10 \mu \mathrm{L}$. The PCR cycling conditions for GPR54 are an initial denaturation and activation at $95^{\circ} \mathrm{C}$ for $5 \mathrm{~min}$, followed by 40 amplification cycles of $95^{\circ} \mathrm{C}$ for $20 \mathrm{~s}$ and $60^{\circ} \mathrm{C}$ for $60 \mathrm{~s}$. The mRNA levels of the target genes were normalised relative to the reference gene $\beta$-actin. A melting curve analysis for each PCR product showed that single products were amplified. The relative expression levels of each gene were obtained using the comparative $\mathrm{Ct}$ method and are depicted as fold change in relation to the control group.

\section{Immunohistochemistry}

Paraffin embedded sections were deparaffinized and rehydrated; antigen retrieval was carried out using citrate buffer using microwate $\left(95^{\circ} \mathrm{C}\right.$ for $\left.30 \mathrm{~min}\right)$. After they reached the room temperature, the sections were washed twice in Tris Buffered Saline (TBS) containing 0.025\% Triton $\mathrm{X}$ and $1 \%$ BSA. Blocking was done using 1\% BSA for $2 \mathrm{~h}$ at room temperature. The sections were incubated overnight at $4{ }^{\circ} \mathrm{C}$ in GPR54 primary antibody (GeneTex) at 1:1000 dilution in TBS containing 1\% BSA. Sections incubated in the same solution without antibody acted as negative control. After washing, the sections were incubated with HRP conjugated seconday antibody (Bioss). The sections were developed using DAB (Sigma) as per standard protocol of incubation with $\mathrm{H}_{2} \mathrm{O}_{2}$ followed by treating with chromogen. Sections were counterstained using H\&E staining, dehydrated and mounted.

Table 1. Primer sequences used for real time PCR analysis

\begin{tabular}{cll}
\hline mRNA & Primer & \multicolumn{1}{c}{ Primer sequence } \\
\hline Rat GPR54 & Forward & GCGGCCACAGATGTCACTTT \\
& Reverse & AGTGGGCAGCGGATAGAG \\
Rat $\beta$-actin & Forward & TGCCGCATCCTCTTCCTC \\
& Reverse & GGTCTTTACGGATGTCAACG \\
\hline
\end{tabular}




\section{Statistics}

SigmaPlot 13.0 (Systat Software Inc.) statistical software was used for Kaplan-Meier survival analysis followed by Gehan-Breslow test. Graphpad Prism 6, version 6.07 was used for ANOVA and $t$-tests, and for plotting the graphs. $p<0.05$ was considered significant. Data are presented as mean \pm standard error mean (SEM).

\section{RESULTS}

\section{Pubertal onset}

Vaginal opening, the external indication of onset of puberty, was observed in control rats from day 40 onwards with the average of $50 \pm 2.5$ days, while kisspeptin treated rats exhibited vaginal opening only from day 50 (average: $58.44 \pm 1.6$ days; $p=0.01, t$-test). Hence, the pubertal onset was significantly delayed in kisspeptin treated rats compared to control rats (Fig. $1 \mathrm{~A} ; p=0.01$, Kaplan-Meier survival analysis). None of the kisspeptin treated rats showed $\mathrm{VO}$ when $50 \%$ of the control rats have already shown VO (Fig. 1B). Interestingly, it appears that, though puberty was delayed, the rate of VO accelerated in treated rats once the drug administration was stopped and the day in which the last animals in both groups showed VO was not much different (day 63 in control vs. day 65 in treated groups). Surprisingly, one of the treated rat showed VO on day 50 i.e. before cessation of chronic treatment. There was no difference in the body weight on the day of VO (i.e. pubertal weight) among both the groups (Fig. 1C).
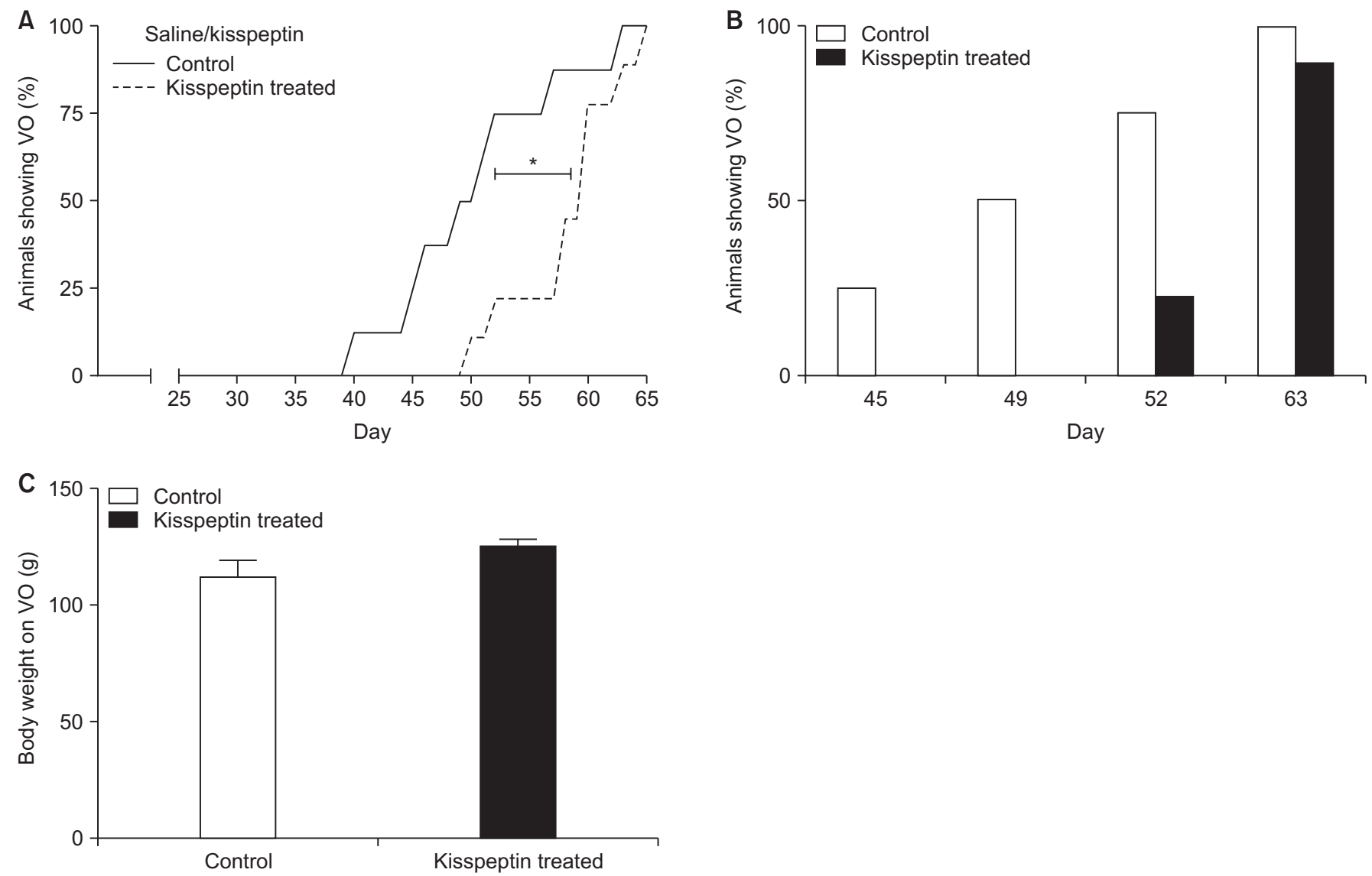

Fig. 1. Effect of chronic peripheral administration of kisspeptin on pubertal onset in female rats. (A) The day of vaginal opening (VO) was noted in rats treated with either saline or kisspeptin from day 25 to day 50 (26 days). Control vs. kisspeptin treated group: $p=0.01$, KaplanMeier survival analysis followed by Gehan-Breslow test. (B) The percentage of animals that have reached puberty was compared between control and treated rats at time point when 25, 50, 75 and 100\% of control rats have shown VO. At the respective time points, only 0 , 0 , 22 and 89\% of kisspeptin treated rats have shown VO ( $p<0.0001$, Chi-square test). (C) Body weight on the day of VO was not different among the two groups. Data expressed as mean \pm SEM. 

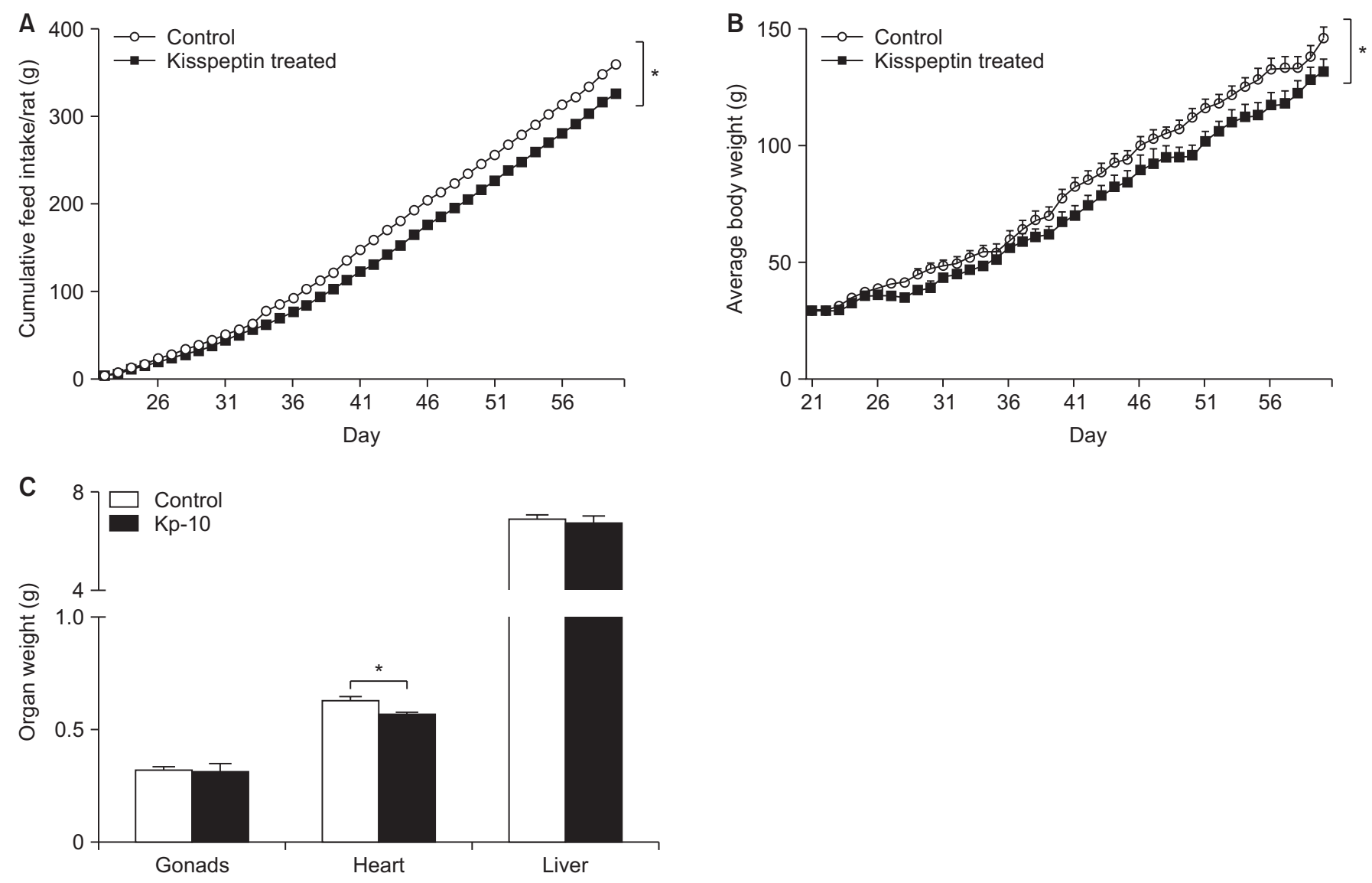

Fig. 2. Effect of chronic peripheral administration of kisspeptin on feed intake and body weight. Saline or kisspeptin was administered from day 25 to day 50. (A) Cumulative feed intake calculated from feed consumed by 2-3 rats housed in cages over the experimental period and averaged per rat. Control vs. kisspeptin treated group: $p<0.001$, two-way ANOVA. (B) Average body weight. Control vs. kisspeptin treated group : $p<0.001$, two-way ANOVA. (C) Weight of gonads (uterus + ovaries), heart and liver. Control vs. kisspeptin treated group in heart weight: $p=0.03$, t-test. Data expressed as mean \pm SEM.
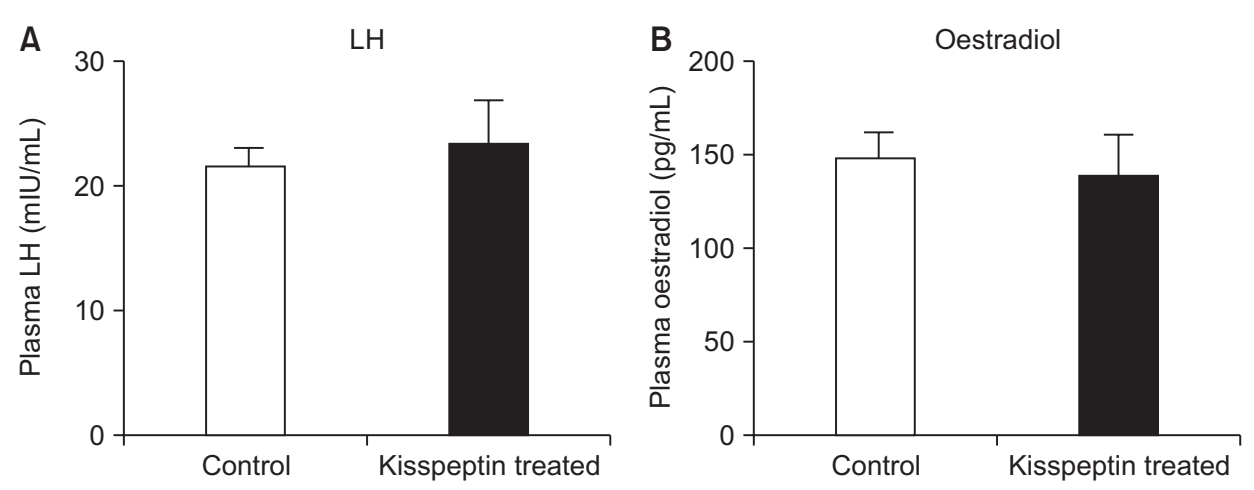

Fig. 3. Effect of chronic peripheral administration of kisspeptin on plasma LH and oestradiol concentration. Saline or kisspeptin (100 nmol i.p) was administered from day 25 to day 50. On day 66, the animals were again treated with either saline or kisspeptin (100 nmol), i.p., and after an hour, blood was collected retro-orbitally to study LH and oestradiol response. There was no difference among the groups in plasma $\mathrm{LH}(\mathrm{A})$ and oestradiol (B) concentrations. Data expressed as mean \pm SEM.

\section{Feed intake and body weight}

Kisspeptin administration significantly reduced feed intake and body weight compared to saline treated controls
(Fig. 2). Cumulative feed intake was significantly less in kisspeptin group compared to saline treated control group ( $p<0.001$, two-way ANOVA; Fig. 2A). The initial body 
weight on day 21 and the daily weight gain were not significantly different between the groups (data not shown). However, the cumulative body weight observed during the course of the experimental period was different among the groups with the animals in kisspeptin group weighing lesser than the control group ( $p<0.001$, two-way ANOVA; Fig. 2B). There was no difference in the organ coefficients of gonads (control vs. treated: $0.2 \pm 0.01$ vs. $0.21 \pm 0.02 \mathrm{~g} /$ $100 \mathrm{~g}$ body weight), heart $(0.39 \pm 0.01$ vs. $0.38 \mathrm{~g} / 100 \mathrm{~g}$ body weight) and liver $(4.34 \pm 0.1$ vs. $4.5 \pm 0.2 \mathrm{~g} / 100 \mathrm{~g}$ body weight) as observed on day 66 (data not shown). However, kisspeptin treated rats had significantly lower weight of heart compared to saline treated controls ( $p=0.03$, $t$-test; Fig. 2C).

\section{Plasma LH and oestradiol}

Rats, treated earlier with either saline or kisspeptin from day 25 to day 50, were administered a single injection of the same on day 66 and blood samples were collected $1 \mathrm{~h}$ after the injections to estimate plasma LH and oestradiol
A
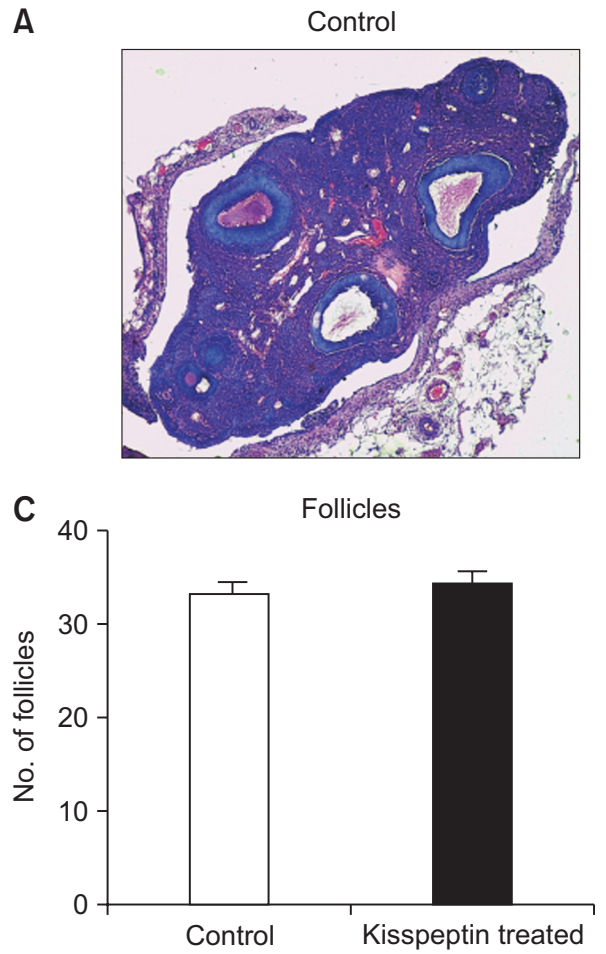

B

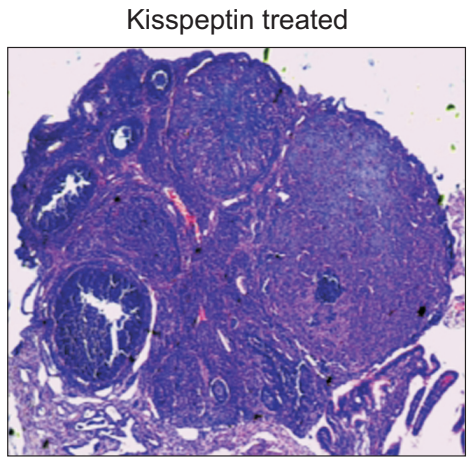

D

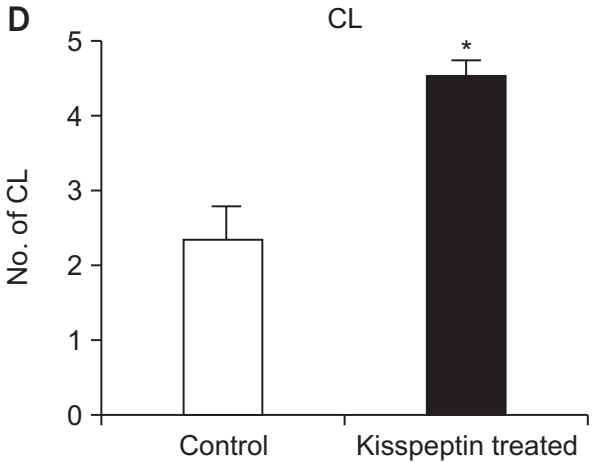

Fig. 4. Effects of chronic kisspeptin administration on the number of ovarian follicles and $\mathrm{CL}$ in rats. Representative histological sections of ovaries from control (A) and kisspeptin treated rats (B). While there is no difference in the number of follicles among the groups (C), kisspeptin treated group had significantly higher number of $\left({ }^{*} p=0.001\right.$, t-test) (D). Data expressed as mean \pm SEM.

\section{A}

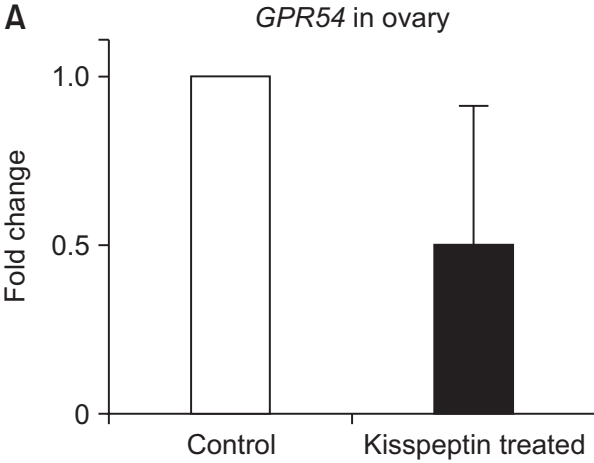

B

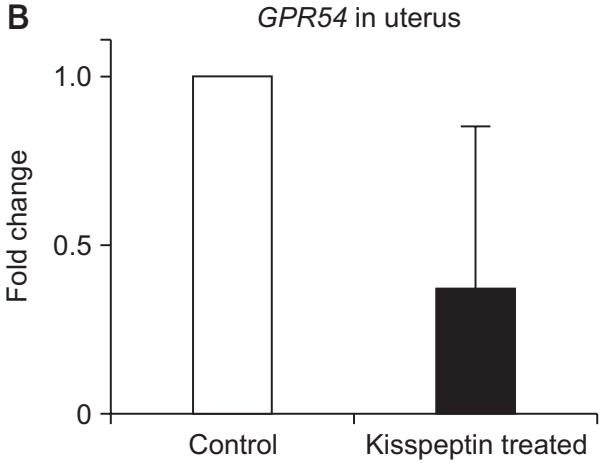

Fig. 5. Effect of chronic peripheral administration of kisspeptin on GPR54 mRNA in gonads. Saline or kisspeptin (100 nmol i.p) was administered from day 25 to day 50. On day 66, the animals were again treated with a single injection of either saline or kisspeptin (100 nmol), i.p., sacrificed after an hour, and gonads collected and snap-frozen for GPR54 real time PCR. Chronic kisspeptin reduced GPR54 expression in ovaries (A) and uteri (B) as compared to saline treated controls. 
concentrations. There was no difference between the control and treated rats in the levels of these hormones (Fig. 3).

\section{Vaginal cytology and histopathology}

Vaginal cytology observations showed that control animals were in various phases of oestrous cycle as expected. However, kisspeptin treated animals were predominantly in metoestrus phase of the cycle. There was no ovarian and uterine histopathology observed in the H\&E stained sections. However, there were more number of corpora lutea $(\mathrm{CL})$ in kisspeptin treated rats compared to controls ( $p=0.001, t$-test; Fig. 4).

\section{GPR-54 mRNA and protein expression profile}

Though there was a reduction in GPR54 mRNA in the gonads, it was not significant (Fig. 5). Besides, the two
A Ovary

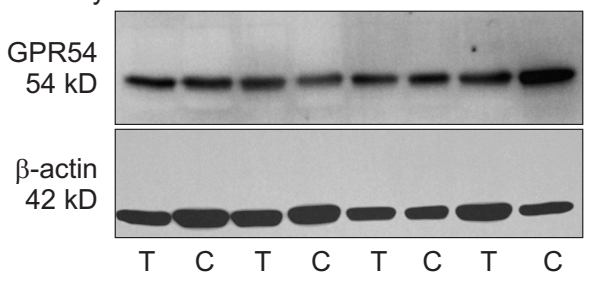

C

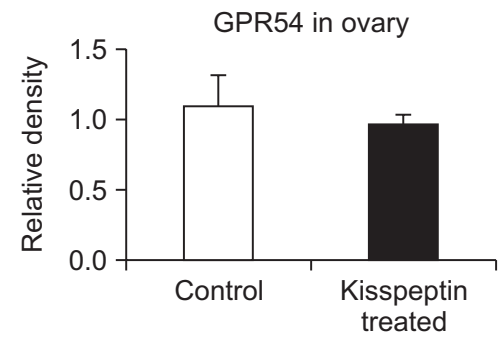

B Uterus

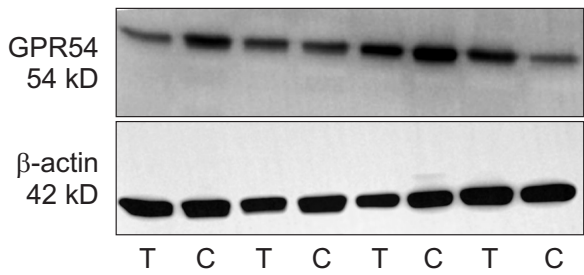

D

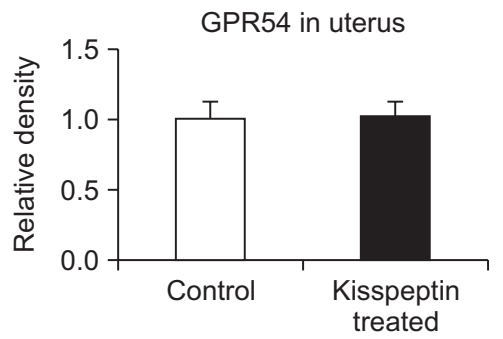

Fig. 6. Effect of chronic peripheral administration of kisspeptin on GPR54 in gonads. Saline or kisspeptin $(100 \mathrm{nmol}$ i.p) was administered from day 25 to day 50 . On day 66 , the animals were again treated with either saline or kisspeptin $(100 \mathrm{nmol})$, i.p., sacrificed after an hour, and gonads were collected. There was no difference among the groups in ovarian ( $A$ and $C$ ) and uterine (B and D) GPR54 expression. Data expressed as mean \pm SEM. C = control; $T$ $=$ kisspeptin treated.

GPR54-ir

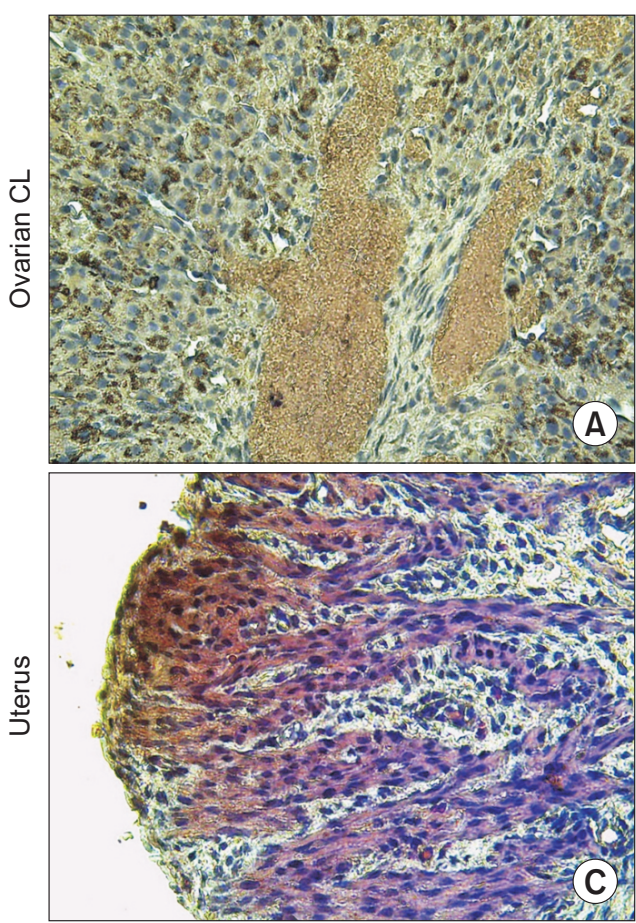

Control

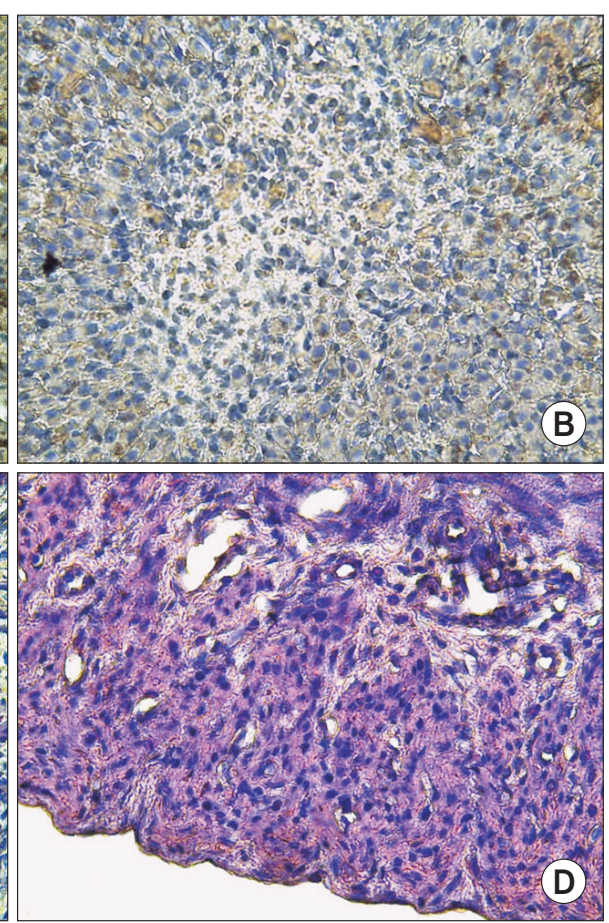

Treated
Fig. 7. Effects of chronic kisspeptin on GPR54-ir in ovaries and uteri. Saline or kisspeptin (100 nmol i.p) was administered from day 25 to day 50 . On day 66, the animals were sacrificed and gonads were collected. GPR54-ir (brown) was detected in the corpus luteum and uterus from controls ( $A$ and $C$ ) and treated ( $B$ and D) animals. A representative section shows that the level of GPR54ir in the $C L$ and uterus was lower in the kisspeptin treated rats (magnification: $40 \times)$. 
groups did not differ in GPR54 protein expression profile (Fig. 6).

\section{Immunohistochemistry}

GPR54-ir was detected in the corpora lutea and uteri from saline and kisspeptin treated animals. At least in some of the animals, it was observed that GPR54-ir was less in the gonads of treated rats compared to control rats (Fig. 7).

\section{DISCUSSION}

Here we show for the first time that chronic high doses of kisspeptin delays puberty in rats. Kisspeptin has earlier been shown to advance puberty in rats when administered at low doses either during a specific window of growth period (i.e. 26-31 days postnatal) or for a prolonged period (26-60 days postnatal) (Navarro et al., 2004; Sahin et al., 2015). However, long term administration of higher doses, as shown in our study, seems to delay puberty, probably by negative feedback inhibition of the hypothalamic neuronal network that govern the whole process or by kisspeptin receptor downregulation or desensitization. It might be noted that the possibility of reduction in feed intake and body weight as a cause for delay in puberty cannot be ruled out.

Human (Tyr-Asn-Trp-Asn-Ser-Phe-Gly-Leu-Arg-Phe$\mathrm{NH}_{2}$ ) and rat (Tyr-Asn-Trp-Asn-Ser-Phe-Gly-Leu-ArgTyr- $\mathrm{NH}_{2}$ ) kisspeptin-10 differs in only one amino acid and human kisspeptin-10 has been shown to advance puberty in SD rats (Sahin et al., 2015). In the same study, pubertal advance was observed even though the animals were treated chronically (26 to 60 days postnatal) (Sahin et al., 2015). However the dose was less (50 pmol) and was administered centrally. Hence, the delay in puberty observed in our study might be specifically due to the higher dose $(100 \mathrm{nmol} / \mathrm{rat}$ per day) administered along with longer duration (26-50 days postnatal). Peripheral (i.p) route of administration of kisspeptin might also have potentially influenced the delay in puberty as kisspeptin receptors are also expressed in non-neuronal tissues such as ovaries (Castellano et al., 2006).

Vaginal opening occurs the day after the first surge of gonadotrophins (Beckman and Feuston, 2003). It may be noted that $\mathrm{VO}$ in control rats spanning over 40 to 63 days postnatal, though appears to be beyond the typical period of 36-37 days postnatal, still falls within the range of 32-109 days (Beckman and Feuston, 2003). Though in most of the treated rats it may be reasoned that the surge of preovulatory gonadotropins might have occurred after removal of possible negative feed-back inhibition by chronic treatment, resulting in VO, it remains unexplainable for the one rat that showed VO on the last day of treatment i.e. before cessation of chronic treatment.

Though the effect of kisspeptin on energy metabolism and body weight remains inconclusive, we found that kisspeptin treated animals had significantly lower body weight compared to controls, probably due to reduced feed intake. Reduced body weight may have also contributed to the delay in VO.

Single injection of kisspeptin at the end of the experiment, given 16 days after the end of chronic administration, failed to increase the plasma LH and oestradiol levels at 60 min post-injection, probably reflecting the levels that have returned back to normal after an acute period of increase (at around 15-20 $\mathrm{min}$ ) as reported in male rats (Thomson et al., 2004).

Our data is inconclusive on suppression of HPG axis via GPR54 downregulation due to chronic kisspeptin administration as we examined the GPR54 expression 16 days after cessation of treatment after all the animals reached puberty. Despite this, we observed that GPR54 mRNA is mildly reduced in gonads in treated rats though it is not significant. However, though GPR54-ir appears to be reduced in treated animals, protein data doesn't show this pattern. Taken together, though our study is novel and for the first time reports delay in puberty upon chronic kisspeptin treatment, it needs further exploration towards understanding the mechanism behind this delay. in high doses. Nonetheless, our study suggests potential use of kisspeptin in nullifying precocious puberty in prone individuals after thorough evaluation of advantages and disadvantages of the therapy. GnRH analogues constitute the gold-standard therapy for central precocious puberty (Latronico et al., 2016). Advantages of kisspeptin analogues, over the current GnRH analogues, for the treatment of central precocious puberty are to be explored.

\section{CONFLICTS OF INTEREST}

The study was conducted at NIAB. However, the authors are not working at the institute at the time of publication. 


\section{ACKNOWLEDGEMENTS}

The authors acknowledge Ms. Shailaja and Dr. Sulekha at National Institute of Nutrition, Hyderabad, India, for microtome sectioning and analyzing gonadal histopathology, respectively. The authors also acknowledge Ms. Rama Devi, NIAB, for animal maintenance and Ms. Shalini, Teena Labs, for animal dissection.

\section{AUTHOR CONTRIBUTIONS}

SV and RH performed the animal experiments. RH performed ELISA. SS performed Western Blot and RT-PCR. MPU performed immunohistochemistry and histology analysis. SV designed the experiments, analyzed and interpreted the results and wrote the manuscript.

\section{AUTHOR'S POSITION AND ORCID NO.}

\author{
S Sathagopam, Project Fellow, \\ https://orcid.org/0000-0003-2249-0883 \\ MP Ullewar, Clinical Evaluation Report Writer, \\ https://orcid.org/0000-0001-8176-7286 \\ R Harne, Postdoctoral Associate, \\ https://orcid.org/0000-0003-3360-1657 \\ S Velmurugan, Post-doctoral Research Scholar, \\ https://orcid.org/0000-0003-0769-8424
}

\section{REFERENCES}

Alcin E, Özcan M, Ayar A, Yilmaz B, Türköz Y, Keleştimur H. 2011. Effects of peripheral administration of kisspeptin on pubertal maturation and serum leptin levels in female rats. Turk Klin Tip Bilim. 31:1477-1483.

Beckman DA and Feuston M. 2003. Landmarks in the development of the female reproductive system. Birth Defects Res. B Dev. Reprod. Toxicol. 68:137-143.

Beltramo M, Dardente H, Cayla X, Caraty A. 2014. Cellular mechanisms and integrative timing of neuroendocrine control of GnRH secretion by kisspeptin. Mol. Cell. Endocrinol. 382:387-399.

Castellano JM, Gaytan M, Roa J, Vigo E, Navarro VM, Bellido C, Dieguez C, Aguilar E, Sánchez-Criado JE, Pellicer A, Pinilla L, Gaytan F, Tena-Sempere M. 2006. Expression of KiSS-1 in rat ovary: putative local regulator of ovulation? Endocrinology 147:4852-4862.

Castellano JM, Navarro VM, Fernández-Fernández R, Nogueiras R, Tovar S, Roa J, Vazquez MJ, Vigo E, Casanueva FF, Aguilar E, Pinilla L, Dieguez C, Tena-Sempere M. 2005. Changes in hypothalamic KiSS-1 system and restoration of pubertal activation of the reproductive axis by kisspeptin in undernutrition. Endocrinology 146:3917-3925.

Fu LY and van den Pol AN. 2010. Kisspeptin directly excites anorexigenic proopiomelanocortin neurons but inhibits orexigenic neuropeptide Y cells by an indirect synaptic mechanism. J. Neurosci. 30:10205-10219.

Irwig MS, Fraley GS, Smith JT, Acohido BV, Popa SM, Cunningham MJ, Gottsch ML, Clifton DK, Steiner RA. 2004. Kisspeptin activation of gonadotropin releasing hormone neurons and regulation of KiSS-1 mRNA in the male rat. Neuroendocrinology 80:264-272.

Latronico AC, Brito VN, Carel JC. 2016. Causes, diagnosis, and treatment of central precocious puberty. Lancet Diabetes Endocrinol. 4:265-274.

Matsui H, Takatsu Y, Kumano S, Matsumoto H, Ohtaki T. 2004. Peripheral administration of metastin induces marked gonadotropin release and ovulation in the rat. Biochem. Biophys. Res. Commun. 320:383-388.

Navarro VM, Castellano JM, Fernández-Fernández R, Barreiro ML, Roa J, Sanchez-Criado JE, Aguilar E, Dieguez C, Pinilla L, Tena-Sempere M. 2004. Developmental and hormonally regulated messenger ribonucleic acid expression of KiSS-1 and its putative receptor, GPR54, in rat hypothalamus and potent luteinizing hormone-releasing activity of KiSS-1 peptide. Endocrinology 145:4565-4574.

Overgaard A, Tena-Sempere M, Franceschini I, Desroziers E, Simonneaux V, Mikkelsen JD. 2013. Comparative analysis of kisspeptin-immunoreactivity reveals genuine differences in the hypothalamic Kiss1 systems between rats and mice. Peptides 45:85-90.

Pineda R, Aguilar E, Pinilla L, Tena-Sempere M. 2010. Physiological roles of the kisspeptin/GPR54 system in the neuroendocrine control of reproduction. Prog. Brain Res. 181:5577.

Pinilla L, Aguilar E, Dieguez C, Millar RP, Tena-Sempere M. 2012. Kisspeptins and reproduction: physiological roles and regulatory mechanisms. Physiol. Rev. 92:1235-1316.

Roa J, Vigo E, García-Galiano D, Castellano JM, Navarro VM, Pineda R, Diéguez C, Aguilar E, Pinilla L, Tena-Sempere M. 2008. Desensitization of gonadotropin responses to kisspeptin in the female rat: analyses of LH and FSH secretion at different developmental and metabolic states. Am. J. Physiol. Endocrinol. Metab. 294:E1088-E1096.

Sahin Z, Canpolat S, Ozcan M, Ozgocer T, Kelestimur H. 2015. Kisspeptin antagonist prevents RF9-induced reproductive changes in female rats. Reproduction 149:465-473.

Stengel A, Wang L, Goebel-Stengel M, Taché Y. 2011. Centrally injected kisspeptin reduces food intake by increasing meal intervals in mice. Neuroreport 22:253-257.

Thompson EL, Amber V, Stamp GW, Patterson M, Curtis AE, Cooke JH, Appleby GF, Dhillo WS, Ghatei MA, Bloom SR, Murphy KG. 2009. Kisspeptin-54 at high doses acutely induces testicular degeneration in adult male rats via central mechanisms. Br. J. Pharmacol. 156:609-625. 
Thompson EL, Murphy KG, Patterson M, Bewick GA, Stamp GW, Curtis AE, Cooke JH, Jethwa PH, Todd JF, Ghatei MA, Bloom SR. 2006. Chronic subcutaneous administration of kisspeptin-54 causes testicular degeneration in adult male rats. Am. J. Physiol. Endocrinol. Metab. 291:E1074-E1082.

Thompson EL, Patterson M, Murphy KG, Smith KL, Dhillo WS, Todd JF, Ghatei MA, Bloom SR. 2004. Central and peripheral administration of kisspeptin-10 stimulates the hypothalamic-pituitary-gonadal axis. J. Neuroendocrinol. 16:850-858.

Tolson KP, Garcia C, Yen S, Simonds S, Stefanidis A, Lawrence A, Smith JT, Kauffman AS. 2014. Impaired kisspeptin signaling decreases metabolism and promotes glucose intolerance and obesity. J. Clin. Invest. 124:3075-3079. 